\title{
Fisiologia do envelhecimento: da plasticidade às consequências cognitivas
}

\author{
Physiology of aging: from plasticity to cognitive \\ consequences
}

\author{
Fisiología del envejecimiento: de la plasticidad a las \\ consecuencias cognitivas
}

\author{
Natália Cochar-Soares ${ }^{1}$, Maicon Luís Bicigo Delinocente², Livia \\ Mendonça Munhoz Dati ${ }^{3}$
}

\begin{abstract}
1.Estudante de Mestrado, Universidade Federal de São Carlos, UFSCAR, Departamento de Gerontologia, São Carlos-SP, Brasil. ORCID: https://orcid.org/0000-0001-8066-5480

2.Estudante de Mestrado, Universidade Federal de São Carlos, UFSCAR, Departamento de Gerontologia, São Carlos-SP, Brasil. ORCID: https://orcid.org/0000-0002-8704-8837

3.Professora Doutora, Universidade Federal de São Paulo, UNIFESP; Departamento de Neurologia e Neurocirurgia; Disciplina de Neurociências; São Paulo-SP, Brasil. ORCID: https://orcid.org/0000-0002-6303-2144
\end{abstract}

\section{Resumo}

O presente artigo apresenta uma revisão de literatura dos principais conceitos, aspectos e achados relacionados ao processo de envelhecimento humano, buscando sintetizar importantes temas por meio da busca de estudos recentes na área. Além disso, o artigo tem foco na discussão de questões associadas à fisiopatologia do Sistema Nervoso Central, função cognitiva e as respectivas consequências decorrentes tanto do envelhecimento saudável quanto do patológico, que neste último caso pode afetar negativamente a autonomia e independência, bem como a qualidade de vida das pessoas idosas. Por fim, o presente trabalho aborda estratégias que visam atuar na prevenção de declínios da função cognitiva.

Unitermos. Envelhecimento; cognição; senescência; senilidade; plasticidade cerebral

\begin{abstract}
This present article was a literature review of the main concepts, aspects and findings related to the human aging process; it was seeking to synthesize important themes through the search for recent studies in the area. In addition, the article focuses on the discussion of issues associated with the pathophysiology of the Central Nervous System, cognitive function and the respective consequences resulting from both healthy and pathological aging, which in the latter case can negatively affect autonomy and independence, as well as quality of life for the elderly. Finally, the present work addresses strategies that aim to prevent cognitive function declines. Keywords. Aging; cognition; senescence; senility; brain plasticity
\end{abstract}

\section{Resumen}

Este artículo presenta una revisión bibliográfica de los principales conceptos, aspectos y hallazgos relacionados con el proceso de envejecimiento humano, buscando sintetizar temas importantes a través de la búsqueda de estudios recientes en el área. Además, el artículo se centra en la discusión de cuestiones asociadas a la fisiopatología del Sistema Nervioso Central, la función cognitiva y las respectivas consecuencias del envejecimiento tanto sano como patológico, que en este último caso pueden afectar negativamente la autonomía e independencia, así como la calidad. de vida para los ancianos. Finalmente, el presente trabajo aborda estrategias que tienen como objetivo prevenir el deterioro de la función cognitiva.

Palabras clave. envejecimiento, cognición, senescencia, senilidad, plasticidad cerebral 


\section{INTRODUÇÃO}

O estudo do envelhecimento pode ser dividido em dois grandes blocos: o envelhecimento humano e 0 envelhecimento populacional. Dentro do contexto humano, podemos dizer que é individual, particular a quem vivencia, resultado de mudanças no organismo como um todo, podendo ser subdividido em três dimensões: biológica, psicológica e social. Já o envelhecimento populacional é caracterizado pelo processo de transição demográfica. Tratase de um fenômeno mundial no qual o aumento da expectativa de vida e queda nas taxas de natalidade e fecundidade são indicadores fundamentais ${ }^{1}$.

Em países desenvolvidos a redução das taxas de mortalidade e fecundidade ocorreram durante um longo período. Isso permitiu o planejamento de estratégias de enfretamento que atendessem às demandas de uma população envelhecida. Em contrapartida, para os países em desenvolvimento, como os da América Latina e Brasil, por exemplo, tais indicadores sofreram um declínio mais acelerado sem que a sociedade tivesse tempo de se planejar para enfrentar tal mudança ${ }^{2-6}$.

No Brasil, há um cenário diferente, mas que causa grandes preocupações. A transição demográfica leva à transição epidemiológica, a qual é denominada pela 
diminuição de doenças infectocontagiosas e aumento de doenças crônicas não transmissíveis, por estas serem mais presentes em idosos. Desse modo, ocorre o deslocamento da maior carga de morbimortalidade da população jovem para os grupos de pessoas mais velhas. Entretanto, os processos acima explicitados ocorrem concomitantemente, se sobrepõem, e apresentam grande variabilidade nas diferentes regiões, o que dificulta o planejamento de um sistema de saúde eficiente $e^{2-4,7}$.

Com esse aumento na prevalência de doenças crônicas e degenerativas, é sabido que se não houver um acompanhamento adequado, a população idosa será alvo de complicações e sequelas que trarão prejuízos da capacidade funcional, limitações na inclusão social, comprometimento da qualidade de vida e o risco aumentado de dependência, institucionalização e morte precoce ${ }^{3-6,8,9}$.

Diante das projeções que indicam que o número de idosos no mundo é crescente com estimativa que em 2050 a população idosa ultrapassará a marca de dois bilhões de pessoas com mais de 60 anos de idade, e com projeções que indicam que esse processo será ainda mais acelerado nos países em desenvolvimento, como é o caso do Brasil, compreender esse cenário e suas particularidades é fundamental para o desenvolvimento de estratégias de enfrentamento $0^{5,6,10}$.

Nessa perspectiva a presente revisão, fruto da disciplina de neurociência - Neuroscience at hand - ofertada pelo Programa de Pós-Graduação em Neurologia/Neurociência da 
Escola Paulista de Medicina, Universidade Federal de São Paulo (EPM/UNIFESP) e resultado de inúmeras discussões acerca do envelhecimento humano e populacional, tem como objetivo explanar acerca da fisiologia do processo de envelhecimento humano, com ênfase ao Sistema Nervoso Central, discutindo conceitos, aspectos associados ao tema, as consequências decorrentes do envelhecimento, bem como algumas estratégias para prevenção de transtornos neurocognitivos, de forma a colaborar para a manutenção da qualidade de vida também na fase da velhice.

\section{MÉTODO}

A presente revisão foi elaborada de modo a atender o Suplemento especial da Revista de Neurociências brasileira. Para as discussões, elaboração e desenvolvimento deste material, os artigos foram extraídos das bases de dados Pubmed, Scielo e Google Acadêmico. Para a busca dos artigos foram consideradas as seguintes palavras-chave, tanto no idioma português quanto no inglês: envelhecimento cerebral, envelhecimento cognitivo, envelhecimento e Sistema Nervoso Central, plasticidade cerebral, fisiologia do envelhecimento, envelhecimento saudável, estimulação cognitiva. Os artigos foram escolhidos de modo que abordassem os respectivos temas e, consequentemente, subsidiassem nossas discussões viabilizando um panorama geral e atual sobre a temática, além de ter sido dada preferência para estudos mais recentes. 


\section{RESULTADOS E DISCUSSÃO \\ Desenvolvimento}

Processo de envelhecimento

O envelhecimento é um processo natural e fisiológico, além de dinâmico, heterogêneo, universal e irreversível, caracterizado por modificações biológicas, sociais e psicológicas, que podem ou não causar perda da autonomia e independência da pessoa, sendo possível observar uma maior vulnerabilidade a patologias ${ }^{11}$.

Grande parte das pessoas desejam alcançar um envelhecimento bem-sucedido, por meio de um estilo de vida saudável. A prática regular de atividade física, usufruir de uma dieta alimentar adequada, não fumar, estão entre as práticas mais comuns para se obter melhor qualidade de vida e maior expectativa de vida ${ }^{11}$.

No entanto, com o passar do tempo ocorrem alterações biológicas inerentes ao envelhecimento, que, independentemente do estilo de vida adotado, podem resultar em alguns prejuízos ao indivíduo, como por exemplo, as modificações no sistema imunológico. Sabe-se que com o processo de envelhecimento há aumento do nível circulante de citocinas inflamatórias que deprimem o sistema imunológico aumentando o risco de infecções. Assim, com o envelhecimento, o sistema tem as respostas imunológicas comprometidas - processo denominado imunossenescência que acarreta maior vulnerabilidade a doenças, físicas ou até mesmo psicológicas e que refletem no estado emocional e social ${ }^{11}$. 
Paralelo às alterações funcionais e cognitivas, o envelhecimento também é marcado pelo excesso de radicais livres, o qual pode danificar o DNA celular, além de causar o estresse oxidativo, que induzirá o encurtamento dos telômeros, além de reduzir a produção de ATP pelas mitocôndrias, intensificando a imunossenescência, atrofia celular e inflamação ${ }^{11}$.

Poucos são os estudos que abordam o funcionamento sensorial e psicomotor na população idosa. É consenso que o avançar da idade compromete a habilidade do sistema nervoso central de realizar o processamento dos sinais vestibulares, visuais e proprioceptivos, os quais são imprescindíveis para a manutenção do equilíbrio corporal e capacidade funcional. A Sarcopenia, por exemplo, ainda que tida como uma alteração, um desfecho adverso do sistema musculoesquelético, tem, como uma das portas de entrada, o declínio funcional que afeta o desempenho de atividades de vida diária, o nível de atividade física e independência. Trata-se de um ciclo vicioso no qual as alterações cognitivas e psicomotoras corroboram com declínio funcional, que impacta no desempenho de atividades, diminuindo massa óssea e muscular, incapacitando e interferindo na qualidade de vida. Assim, o quadro se agrava, há um declínio de força neuromuscular e mais atividades são comprometidas ${ }^{12}$.

Quanto ao envelhecimento psicológico, são reportadas modificações comportamentais e emocionais decorrentes das mudanças que ocorrem não somente à função física, como também ao papel social. Na velhice, a diminuição do 
papel social aumenta o isolamento e acarreta diversos desfechos negativos à saúde mental, como a depressão, ansiedade e insônia, que comprometem a longevidade e o bem estar. Essas lesões orgânicas provocadas por determinado fator emocional, também agravam ou até mesmo propiciam o desenvolvimento de outras doenças psicossomáticas como hipertensão e distúrbios gastrointestinais, como a úlcera ${ }^{12}$.

No envelhecimento social, um componente fundamental é a idade social, intimamente ligada a mudanças nos papeis que o indivíduo possui perante à sociedade. Ao longo dos anos, comumente o idoso perde papeis e funções sociais que o afasta do contato e relações com outras pessoas. A aposentadoria, por exemplo, é um grande fator que contribui para o isolamento, denominado morte social e a reinserção no mercado de trabalho ou desenvolvimento de atividades comunitárias ou voluntariado, tem sido estratégias utilizadas na reversão de mais esse fator ${ }^{12}$.

Por fim, as alterações cerebrais estruturais e funcionais também compõem o processo de envelhecimento como a atrofia da massa cinzenta e branca, além das conexões funcionais e de neurotransmissão, ainda que não necessariamente impliquem em dificuldades nas rotinas do idoso. Por outro lado, distúrbios neurodegenerativos graves, como as demências, causam dificuldade na realização de atividades do cotidiano, levando ao comprometimento da autonomia e independência ${ }^{13}$. 
Envelhecimento cerebral

A investigação neurocientífica se faz cada vez mais necessária para a compreensão das mudanças morfológicas, funcionais e neurocognitivas do cérebro, que se associam ao processo de envelhecimento humano ${ }^{14}$. Até o momento foram identificadas modificações no cérebro como, por exemplo, a redução no volume de massa cinzenta (atrofia cerebral), nas regiões do córtex pré-frontal, lobo temporal e hipocampo ${ }^{15,16}$.

Tal condição pode ocorrer devido à morte neuronal, redução do tamanho dos neurônios, como também da densidade sináptica. Outra possível explicação é o acúmulo de proteína beta amiloide, comum tanto em pacientes com doença de Alzheimer quanto em idosos com declínio cognitivo moderado, porém estudos recentes já encontraram este acúmulo também em idosos cognitivamente saudáveis; sendo assim, tal acúmulo em pessoas saudáveis pode estar associado ao risco aumentado de desenvolver comprometimento cognitivo com o passar do tempo ${ }^{14}$.

A atrofia cerebral pode ocorrer vários anos antes do aparecimento de déficits cognitivos, o que pode auxiliar no desenvolvimento de biomarcadores para a previsão de declínio cognitivo. A mudança nas medições do volume da substância cinzenta frontal e temporal, bem como atrofia do hipocampo influenciam de maneira negativa no desempenho da memória episódica e da função executiva. Já o volume do hipocampo está associado a modificações na função executiva ${ }^{17,18}$. 
Ademais, a atrofia do córtex entorrinal e hipocampal é reconhecida como uma característica de imagem da doença de Alzheimer, sendo que a atrofia do hipocampo é considerada fator de risco para declínio cognitivo e demência quando presente no processo normal de envelhecimento ${ }^{19}$.

Levando em consideração que os neurônios não funcionam separadamente, mas sim em conjunto com uma rede sofisticada composta por células gliais, vasculares e periféricas, é importante que haja o entendimento do processo de envelhecimento cerebral como um todo, uma vez que os distúrbios cerebrais podem trazer consequências que interfiram no bem-estar do indivíduo à medida que causam perda gradual da qualidade de vida, além de serem percursores de uma morte precipitada ${ }^{20}$.

O envelhecimento neuronal está atrelado a diversas alterações morfológicas dos neurônios, em que se pode citar a diminuição em seu tamanho, diminuição nas espinhas dendríticas, comprometimento da comunicação entre os neurônios, além de ocorrência de processos inflamatórios, estresse oxidativo e alteração na biodisponibilidade de neurotransmissores. Há evidências de que os receptores AMPA (amino-3-hidroxi-5-metil-4 isoxazolproprionato), os quais estão envolvidos com a memória, aprendizagem e plasticidade sináptica, sofrem redução na quantidade disponível ao decorrer do envelhecimento ${ }^{14}$.

Além disso, estudos demonstram que o receptor NMDA (N-metil-D-aspartato), um dos principais receptores de glutamato, e que estão em sua maior parte localizados em 
regiões hipocampais, exercem um importante papel no desenvolvimento do Sistema Nervoso Central e no envelhecimento cerebral, principalmente na manutenção de células neuronais, na estrutura de axônios e dendritos, na plasticidade sináptica e na sinaptogênese, bem como interferem na memória e aprendizagem. Dessa forma, é essencial a ampliação de estudos a fim de compreender a relação entre o processo de envelhecimento e alterações das funções cerebrais ${ }^{21,22}$.

Apesar de a neurobiologia do envelhecimento cerebral não ser ainda totalmente conhecida, pode-se afirmar que possui uma natureza multifatorial, impactada pelo aumento do estresse oxidativo (decorrente do desequilíbrio entre agentes oxidantes e antioxidantes devido ao excesso de radicais livres) e níveis de inflamação crônica que contribuem para o declínio cognitivo, bem como mudanças no metabolismo da glicose que inferem na diminuição da absorção neuronal de glicose e alterações na função das mitocôndrias. Ainda, outros fatores que se correlacionam com o declínio cognitivo são as alterações neuroinflamatórias que envolvem ativação microglial e nível elevado de citocinas inflamatórias ${ }^{16}$.

O declínio no desempenho cerebral tende a manifestarse mais rapidamente a partir dos 50 anos de idade e é provocado por modificações no sistema nervoso central que incluem: alterações neuroanatômicas (atrofia cerebral, morte neuronal), alterações na neurotransmissão (declínio na transmissão colinérgica, diminuição da síntese 
dopaminérgica, diminuição da síntese de catecolaminas); alterações neurofisiológicas (diminuição do fluxo sanguíneo cerebral), entre outras ${ }^{23}$. 0 envelhecimento também acarreta a redução do comprimento dos axônios, que estão relacionados à substância branca e permitem a comunicação e coordenação da atividade de diferentes áreas encefálicas. Os neurotransmissores relacionados à depressão e ansiedade, como a dopamina e serotonina, por exemplo, também diminuem ao longo da vida e têm forte relação com o declínio nas funções cognitiva e motora ${ }^{24}$.

Outro ponto importante é que o neurotransmissor acetilcolina impacta fortemente no desempenho da memória, uma vez que a função do hipocampo é significativamente afetada pela disfunção colinérgica. Foram observadas redução na quantidade de receptores colinérgicos no hipocampo e na ligação de acetilcolina em pacientes com doença de Alzheimer ${ }^{25}$.

Os astrócitos, fundamentais para a homeostase, defesa e regeneração do Sistema Nervoso Central, tendo em vista que a perda da função astroglial implica no envelhecimento encefálico e maior chance de doenças neurodegenerativas ${ }^{26,27}$.

As micróglias, células imunológicas do cérebro, atuam em resposta à inflamação sistêmica e a diversos estressores fisiopatológicos, além de contribuir para a integridade da barreira hematoencefálica, estrutura essa que, devido à senescência celular, sofre comprometimento de suas funções, fazendo com que citocinas inflamatórias adentrem 
ao cérebro. Consequentemente, essas citocinas levam a danos em células neurais e gliais, possivelmente causando doenças relacionadas à idade 26 .

Perante à condição da matéria branca, pode-se dizer que muitas vezes as pequenas lesões ocorridas em áreas da substância branca estão ligadas a fatores cerebrovasculares, que acarretam na diminuição da velocidade e fluxo de informações. Essas alterações cerebrovasculares ou hemodinâmicas resultam em maior prevalência de pequenos infartos 28 .

Vale ressaltar que, a perda de substância branca está relacionada com a quebra de bainhas de mielina e alterações nos oligodendrócitos, sendo que tais mudanças correspondem ao aumento da neuroinflamação e do estresse oxidativo, que consequentemente afeta o desempenho cognitivo ${ }^{28}$.

Por fim, sabe-se que ao decorrer do envelhecimento cerebral acontece perda contínua de neurônios e redução do volume cerebral e que a disfunção do sistema nervoso tem relação com processos patológicos, em especial doenças neurodegenerativas ${ }^{12}$.

\section{Função cognitiva}

Como visto anteriormente, a redução de células nervosas prejudica a conexão e sinapses por neurotransmissores, que aliada à deterioração da matéria branca e cinzenta no lobo frontal e temporal, afeta a função cognitiva, responsável pelo desempenho em tarefas de 
coordenação, planejamento, memória, pensamento, julgamento, entre outras ${ }^{11}$.

A cognição é considerada um processo de aquisição de conhecimentos através de domínios cognitivos: memória e aprendizagem, função executiva, linguagem, atenção, perceptomotor e cognição social, sendo então essencial para a realização de atividades diárias e melhoria da qualidade de vida ${ }^{29}$.

Até o momento observou-se que um pior desempenho de função executiva foi associado a menor volume do córtex pré-frontal. Enquanto a atrofia do hipocampo e redução do volume cerebral têm sido relacionadas à piora na memória. Ademais, atrofia da massa cinzenta tem forte impacto na aceleração do declínio da cognição global ${ }^{16}$.

Para além, o aumento da idade associa-se ao menor desempenho em tarefas cognitivas, sendo que a memória é um dos domínios mais afetados na velhice, devido à diminuição na capacidade para codificar informações recentes, sendo os lapsos de memória as principais queixas por parte dos idosos ${ }^{15,16}$.

Já o comprometimento da função executiva pode acarretar declínio no desempenho de atividades instrumentais, e o domínio cognitivo linguagem geralmente permanece estável ao decorrer dos anos, podendo até mesmo haver um aumento de vocabulário ${ }^{15}$.

Embora haja inúmeros fatores negativos atrelados ao envelhecimento cerebral, algumas funções cognitivas ainda permanecem estáveis ao longo da vida, como é o caso da 
linguagem no que tange ao aumento do vocabulário e a formação de conhecimento geral adquirido. Esse fato é animador na busca constante pela manutenção das habilidades cognitivas ao longo de toda a vida ${ }^{28}$.

As alterações na cognição são decorrentes do próprio processo de envelhecimento, que quando não implica limitação na capacidade de exercer as atividades de vida diária pode-se considerar um envelhecimento normal ou possivelmente tratar-se de um transtorno neurocognitivo leve, condição que ainda pode ser revertida. No entanto, caso haja declínio funcional que prejudique a independência do indivíduo, deve-se averiguar um possível diagnóstico de demência ${ }^{30}$.

Os domínios mais afetados pelo envelhecimento são a função executiva, coordenada pelo córtex cerebral, e memória de trabalho, que é responsável pelo armazenamento temporário de informações recentes. Os fatores que implicam nas alterações cognitivas são: genéticos, saúde, grau de escolaridade, comportamento e humor, treino cognitivo e convívio social ${ }^{18,29}$.

A amnésia é a falha ou falta de memória que pode ocorrer em qualquer faixa etária, sendo que é mais prevalente em pessoas com mais de 50 anos, por apresentar patologias que podem estar relacionadas a tais alterações de memória ${ }^{31}$.

Durante 0 processo de envelhecimento podemos observar diferenças individuais significativas, pois alguns idosos mantêm a maior parte de suas habilidades cognitivas 
ao longo de toda a vida, enquanto outros indivíduos experimentam declínio na função cognitiva ou até mesmo algum tipo de demência ${ }^{18}$.

Apesar da existência de possibilidades de intervenções como, por exemplo, a estimulação cognitiva e abordagens farmacológicas, que conseguem atenuar o declínio em certos domínios cognitivos, a prevenção e reversão do comprometimento cognitivo continua sendo um desafio para a área da saúde ${ }^{18}$.

\section{Doenças neurodegenerativas}

No que tange a demências, estas são derivadas da degeneração de áreas corticais e do hipocampo, bem como caracterizadas por um declínio na função cognitiva de modo que este afete a vida social do indivíduo, tendo sua prevalência aumentada conforme o avanço da idade ${ }^{30}$.

Existem vários tipos de demência, no entanto a mais comum mundialmente é a Doença de Alzheimer, a qual é degenerativa e causa distúrbio na memória, e outras funções intelectuais como desorientação espacial, além de alteração de humor e comportamento. No início são afetadas as memórias mais recentes, sendo que as mais antigas tendem a ficar preservadas por um período maior de tempo ${ }^{13,15,31,32}$.

O envelhecimento contribui para a redução do fluxo sanguíneo para diversos órgãos vitais, podendo ocasionar atrofia e perda de função. No caso do sistema nervoso central, devido ao envelhecimento vascular cerebral é possível ocorrer perda da integridade da barreira 
hematoencefálica, prejudicando assim a cognição e a condição motora. O comprometimento cognitivo vascular ou demência vascular são os principais exemplos de disfunção cognitiva decorrente de hipoperfusão cerebral ${ }^{33}$.

A doença de Parkinson é a segunda doença neurodegenerativa mais comum do envelhecimento, atrás apenas da doença de Alzheimer. Esta é ocasionada pela morte de neurônios dopaminérgicos na substância negra localizada no mesencéfalo ${ }^{23}$.

É importante salientar que o nível de escolaridade tem papel fundamental no risco para desenvolver comprometimento da função cognitiva, pois quanto maior a escolaridade do indivíduo, maior a reserva cognitiva, podendo então retardar os transtornos neurocognitivos leves e demências ${ }^{31}$.

A reserva cognitiva diz respeito ao armazenamento de habilidades adquiridas ao longo da vida, o que permite resistir a prejuízos e danos cerebrais caso algum tipo de demência venha se desenvolver, além de desenvolver estratégias de compensação para se adaptar diante de limitações advindas. Dessa forma, a doença evolui mais lentamente que o normal23,31.

Além da reserva cognitiva, hábitos de vida saudáveis exercem grande influência na prevenção de demência, como a prática regular de exercícios físicos, atividades cognitivas por meio de leituras, jogos de raciocínio, aprendizado de um novo idioma ou música, manutenção de vínculos sociais, a fim de preservar a mente saudável ${ }^{31}$. 


\section{Estimulação cognitiva}

A estimulação cognitiva em idosos, também conhecida como treino cognitivo, oferece benefícios na performance da cognição global, uma vez que tem influência na preservação da plasticidade cerebral permitindo assim o aprendizado de novas competências e habilidades. Sendo assim, é utilizada para a reorganização e reabilitação do indivíduo devido ao fato de auxiliar na formação de novas conexões que contribuem no bom desempenho das atividades cotidianas ${ }^{34}$.

A estimulação cognitiva compreende um conjunto de estratégias e exercícios com o intuito de aprimorar o desempenho de múltiplos domínios cognitivos, ou de apenas um domínio em específico, podendo ser implementados em grupo ou individualmente, por determinado período de tempo. Tais exercícios consistem na realização de atividades como treinamento de memória, raciocínio, resolução de problemas, habilidades de leitura, artesanato, jogos, entre outros 35 .

Dessa forma, tem como objetivo o empoderamento das pessoas que vivenciam alterações cognitivas, uma vez que fornecem estratégias e adaptações para melhoria do dia-adia do indivíduo, bem como de seus familiares ${ }^{35}$.

Intervenções não farmacológicas são fundamentais para a prevenção de demência, além de que estudos têm mostrado uma correlação entre o envolvimento em atividades mentais complexas e redução da atrofia do volume do hipocampo ${ }^{36}$. 
Ainda, vale ressaltar que embora seja ideal iniciar práticas saudáveis desde o início da vida, há evidências de que aumentar a atividade física e cognitiva na velhice traz também inúmeros benefícios ${ }^{36}$.

Apesar de ser sabido que a estimulação cognitiva pode prevenir transtornos neurocognitivos, ainda não se tem 0 conhecimento sobre como esse processo de proteção ocorre. Alguns estudos até o momento sugerem que as atividades cognitivas agem no fortalecimento do funcionamento da plasticidade neural e reserva cognitiva ${ }^{36}$.

O ambiente é um fator externo extremamente importante para a fonte de experiência cerebral, pelo fato de estimular a formação e manutenção da reserva cognitiva ao longo da vida, além de fatores ligados à escolaridade, trabalho e lazer, pois permitem o crescimento neuronal e a neuroplasticidade ${ }^{37}$.

Ainda, pesquisas sugerem que redes neurais têm papel determinante na manutenção da saúde cognitiva durante o envelhecimento saudável, e que quando exercida a estimulação cognitiva, os idosos possuem capacidade de aprender e aplicar estratégias de memória em suas atividades cotidianas, reforçando assim a existência da plasticidade da memória na velhice, ou seja, a possibilidade de compensação dos déficits cognitivos no envelhecimento saudável ${ }^{37}$. 
Reserva cognitiva, Neuroplasticidade e Neurogênese

A capacidade de regeneração do cérebro é dividida em dois processos: neurogênese e neuroplasticidade, cujo objetivo é compensar as perdas. A neurogênese é a capacidade de produção de novos neurônios, principalmente por estimulação cognitiva, enquanto a neuroplasticidade está relacionada a capacidade de formar novas conexões (sinapses), ou seja, se adaptar a mudanças, gerando novas informações e reestabelecendo comunicações perdidas ${ }^{15,29}$.

O Sistema Nervoso Central tem alta capacidade de adaptação, uma vez que as vias de comunicação denominadas sinapses podem se regenerar até a última fase da vida29.

A neuroplasticidade é caracterizada pela reserva fisiológica do sistema nervoso para promover capacidade de reorganização, sendo crucial para o bom funcionamento do cérebro, pois pode compensar a perda neuronal, principalmente no hipocampo; sendo assim, estimulação de aprendizado e adaptação é importante para melhoria da função cognitiva ${ }^{12,23}$.

O estímulo do ambiente em que a pessoa vive aumenta significativamente o número de células recém-nascidas, melhorando a função cognitiva, como a velocidade de aprendizagem ${ }^{38}$.

Alguns estudos têm observado mudanças patológicas no cérebro, porém com desempenho cognitivo preservado. Dessa forma, instiga as maiores investigações acerca da 
reserva cerebral e reserva cognitiva na manutenção e compensação do cérebro ${ }^{39}$.

A particularidade dos transtornos neurodegenerativos em que uma pessoa pode ter demência enquanto outra da mesma idade estar totalmente preservada cognitivamente pode ser explicada pela reserva cognitiva, que consiste no acúmulo de habilidades, conhecimento e experiências adquiridas ao longo da vida. O nível de escolaridade exerce forte influência na capacidade cognitiva em idosos, ou seja, quanto maior o grau de instrução, maior sua reserva cognitiva. Desse modo, pessoas com maior reserva cognitiva podem suportar mais as lesões antes de manifestar uma deficiência cognitiva, sendo então capaz de diminuir os efeitos de doenças cerebrovasculares, bem como da doença de Alzheimer ${ }^{19,39}$.

Além disso, há evidências de que exercícios físicos e padrão alimentar saudável por meio de restrição calórica induzem a neurogênese em adultos e idosos. Em contrapartida, neuroinflamação, estilo de vida não saudável, estresse oxidativo e lesão no cérebro afetam negativamente a neurogênese ${ }^{40}$.

Envelhecimento cognitivo saudável

Algumas habilidades cognitivas como, por exemplo, o vocabulário, não sofrem influência do envelhecimento cerebral e até melhoram com o avançar da idade. No entanto, mesmo diante de domínios cognitivos que 
normalmente são comprometidos, há uma heterogeneidade na forma e intensidade com que o declínio ocorre ${ }^{41}$.

Enquanto as mudanças mais relacionadas ao envelhecimento patológico concentram-se nos lobos temporais e na diminuição do volume do hipocampo, o volume cerebral começa a reduzir após os 20 anos de idade, principalmente na região do córtex pré-frontal, o que é considerado normal do processo de envelhecimento, sendo que tal processo associa-se a declínios em determinadas habilidades cognitivas como velocidade de processamento, memória e função executiva ${ }^{41}$.

Salienta-se também que, a maioria dos idosos não desenvolverão demência ou nem mesmo transtorno neurocognitivo leve, entretanto é importante estar atento às mudanças e sinais de modo que sejam detectados indícios de declínio patológico com antecedência ${ }^{41}$.

Sabe-se que o envelhecimento saudável é caracterizado pela aplicação de medidas ligadas aos comportamentos e estilo de vida, como a prática regular de atividade física e a manutenção de uma alimentação saudável, as quais são determinantes para a promoção de um envelhecimento bemsucedido ${ }^{42,43}$.

A prática de exercícios físicos tem demonstrado ganhos na otimização da plasticidade cerebral e reserva cognitiva, contribuindo assim para a preservação da cognição e compensação de alterações que ocorrem com o envelhecimento, dado que possibilitam a recuperação e/ou prevenção de danos cerebrais ${ }^{29}$. 
Há evidências que comprovam o potencial de atividades de lazer com estímulo cognitivo, que é capaz de reduzir o risco de declínio cognitivo e de demência. Tais atividades foram associadas a melhorias na memória, velocidade de processamento e função executiva ${ }^{23}$.

Ademais, o exercício físico contribui para o alívio do estresse e melhora do humor, prevenindo transtornos psíquicos e aumentando a imunidade ${ }^{11}$. Outro ponto importante é o fato de que a atividade física pode auxiliar na redução do impacto, que possíveis consequências do envelhecimento psicológico possam exercer na vida cotidiana do indivíduo ${ }^{12}$.

A prática de atividade física é também capaz de estimular a circulação sanguínea cerebral e crescimento neuronal, que consequentemente reduz o acúmulo de radicais livres, atua na preservação da plasticidade neuronal, como também aumenta as sinapses e receptores dendríticos. Além disso, o envolvimento social contribui para a prevenção do declínio cognitivo, visto que tais atitudes auxiliam a manutenção da autonomia e independência da pessoa idosa, impactando positivamente no bem-estar de saúde geral ${ }^{15}$.

$O$ envolvimento em atividades de lazer cognitivas, bem como de interação social, como participação em eventos, comunicação entre amigos e familiares são capazes de melhorar a função cognitiva em pessoas idosas ${ }^{19}$.

A nutrição também exerce um papel fundamental na prevenção do comprometimento cognitivo. Pode-se citar como exemplos bem sucedidos: a estratégia de restrição 
calórica e a dieta do mediterrâneo; ambas são benéficas quanto à manutenção da saúde e bem-estar, ressaltando a importância e necessidade do acompanhamento com um profissional nutricionista ${ }^{42,43}$.

Para além, a alimentação saudável permite a estruturação de neurotransmissores e evita mecanismos acompanhados por patologias e que estão associados ao envelhecimento, como inflammaging, aumento do estresse oxidativo e alterações epigenéticas ${ }^{11,42,43}$.

A forma de alimentação mais estudada é a dieta do mediterrâneo, cuja dieta é baseada na ingestão de frutas, legumes, cereais, azeite, consumo moderado de vinho tinto e baixo consumo de carne vermelha e laticínios; esta traz inúmeros benefícios cerebrocardiovasculares, por conta do efeito hipoglicemiante, proteção contra inflamação, contra agregação plaquetária e contra o estresse oxidativo ${ }^{23}$.

Aliada à atividade física, a alimentação saudável também tem a capacidade de modular o sistema imunológico para defesa de processos neuroinflamatórios e neurodegenerativos decorrentes da doença de Alzheimer, que podem agravar o prejuízo da função cognitiva ${ }^{34,44}$.

Assim, exercícios físicos, padrões saudáveis de dieta alimentar e enriquecimento ambiental desempenham um papel neuroprotetor ao mediar os efeitos antiinflamatórios, promover a neurogênese e regular a micróglia. Entretanto, determinar a verdadeira função e importância da micróglia no início e durante a progressão de doenças 
neurodegenerativas constitui um desafio atual em áreas de pesquisas científicas ${ }^{45}$.

\section{CONSIDERAÇÕES FINAIS}

O processo de envelhecimento e as implicações ao Sistema Nervoso Central (SNC) integram o conteúdo da revisão apresentada. De modo geral, temos que o envelhecimento humano se trata de um processo heterogêneo e multifatorial, que, embora universal, pode ser vivenciado de diferentes maneiras dadas algumas particularidades, intrínsecas entre os indivíduos que experimentam essa fase da vida, como as alterações biológicas, psicológicas e aspectos sociais. No entanto, ainda que determinantes para o curso do envelhecimento saudável ou patológico - podem sofrer influência de outros fatores, serem modificadas e, consequentemente, alterar esse curso.

Mesmo que multidimensional, também é notória a estreita ligação entre esses domínios, alterações e implicações, principalmente ao que tange o SNC. Função motora, sensitiva e integradora resumem a influência que esse sistema exerce em relação ao corpo humano. Assim, com o processo de envelhecimento em curso, modificações/limitações físicas como um declínio da força neuromuscular, redução de massa muscular, lentidão, alterações do equilíbrio, dificuldade na realização de atividades cotidiana, déficit cognitivo e neuronal, compartilham de mecanismos fisiopatológicos comuns e 
contribuem para incapacidade funcional, deterioram qualidade de vida e reduzem o nível de independência e autonomia.

Nessa perspectiva, destacam-se as estratégias que buscam a neuroplasticidade, uma das habilidades do SNC que indica a capacidade de modificar não somente sua estrutura, como seu funcionamento em resposta às necessidades advindas dessas alterações. Desse modo, resumidamente pode se dizer que neuroplasticidade proporciona melhor desempenho cognitivo, reforçando a capacidade de o indivíduo adquirir e usar informação, a fim de adaptar-se às demandas do meio ambiente. Assim, estimulação cognitiva e sua associação bons hábitos comportamentais e estilo de vida tem se mostrado eficaz ao que tange a neuroplasticidade e os processos que a permeiam e, respectivamente, podem favorecer para 0 envelhecimento mais saudável e bem-sucedido.

\section{REFERÊNCIAS}

1.Dantas EHM, Santos CAS. Aspectos biopsicossociais do envelhecimento e a prevenção de quedas na terceira idade. Joaçaba: Editora Unoesc; 2017, 330 p.

2.Kalache A, Veras RP, Ramos LR. O envelhecimento da população mundial: um desafio novo. Rev Saúde Púb 1987;21:200-10. https://doi.org/10.1590/S0034-89101987000300005

3. Ramos LR. Fatores determinantes do envelhecimento saudável em idosos residentes em centro urbano: Projeto Epidoso. Cad Saúde Púb 2003;19:793-8. https://doi.org/10.1590/S0102-311X2003000300011 4.Alexandre TS. Sarcopenia e dinapenia como preditores de incapacidade e óbito em idosos residentes no Município de São Paulo (Tese). São Paulo: Faculdade de Saúde Pública, Universidade de São Paulo; 2013. https://doi.org/10.11606/T.6.2013.tde-13112013$\underline{095646}$ 
5. World Health Organization. Ageing and health. Fact sheet. 2015 (acessado em 2021). Disponível em: http://www.who.int/mediacentre/factsheets/fs404/en

6. World Health Organization. Decade of healthy ageing: baseline report. 2020 (acessado em 2021). Disponível em: https://www.who.int/initiatives/decade-of-healthy-ageing

7. Frenk J, Frejka T, Bobadilla JL, Stern C, Lozano R, Sepúlveda J, et al. La transición epidemiológica en América Latina. Bol Oficina Sanitaria Panam 1991; 111:485-96.

https://iris.paho.org/handle/10665.2/16560

8. Fried LP, Tangen CM, Walston J, Newman AB, Hirsch C, Gottdiener J, et al. Frailty in older adults: evidence for a phenotype. J Gerontol A Bio Sci Med Sci 2001;56:M146-57.

https://doi.org/10.1093/gerona/56.3.m146

9.Guralnik JM. Assessment of physical performance and disability in older persons. Muscle Amp Nerve 1997;20:14-6. https://doi.org/10.1002/(SICI)1097-4598(1997)5+<14: :AID-

MUS4>3.0.CO;2-M

10.Instituto Brasileiro de Geografia e Estatistica. Mudança demográfica no Brasil no Início do Século XXI: subsídios para as projeções da população. Rio de Janeiro: IBGE; 2015.

11.Macena WG, Hermano LO, Costa TC. Alterações fisiológicas decorrentes do envelhecimento. Rev Mosaicum 2018;15:223-38. https://doi.org/10.26893/rm.v15i27.64

12.Dantas EHM, Santos CAS. Aspectos biopsicossociais do envelhecimento e a prevenção de quedas na terceira idade. Joaçaba: Unoesc; 2017.

13.Toepper M. Dissociating Normal Aging from Alzheimer's Disease: A View from Cognitive Neuroscience. J Alzheimers Dis 2017;57:331-52. https://doi.org/10.3233/JAD-161099

14.Pereira T. A função cognitiva no Envelhecimento. Instituto Politécnico de Coimbra IPC. 2019 (acessado em 2021). Disponível em: http://hdl.handle.net/10400.26/32920

15. Konflanz F, Costa K, Mendes T. A neuropsicologia do envelhecer: as "faltas" e "falhas" do cérebro e do processo cognitivo que podem surgir na velhice. Psicologia Pt 2016 (Acessado em 2021). Disponível em: http://www.psicologia.pt/artigos/textos/A1103.pdf

16. Carmona KC. Variáveis associadas ao envelhecimento cerebral bem sucedido em uma amostra de idosos muito idosos da comunidade (Tese). Belo Horizonte: Universidade Federal de Minas Gerais. 2018. http://hdl.handle.net/1843/FRSS-BB2KS7

17.Alijondi R, Szoeke C, Steward C, Yates P, Desmond P. A decade of changes in brain volume and cognition. Brain Imag Behav 2018;13:554-63. https://doi.org/10.1007/s11682-018-9887-z

18.Cohen RA, Marsiske MM, Smith GE. Neuropsychology of aging. Handbook Clin Neurol 2019;167:149-80. https://doi.org/10.1016/B978-0-12-804766-8.00010-8

19. Murray AD, Staff RT, McNeil CJ, Salarirad S, Ahearn TS, Mustafa N, et al. The balance between cognitive reserve and brain imaging 
biomarkers of cerebrovascular and Alzheimer's diseases. Brain 2011;134:3687-96. https://doi.org/10.1093/brain/awr259

20 .Wyss-Coray T. Ageing, neurodegeneration and brain rejuvenation. Nature 2016;539:180-6. https://doi.org/10.1038/nature20411

21.Müller GAS. Análise proteômica do hipocampo de camundongos submetidos ao tratamento com $\mathrm{N}$-metil-D-aspartato (NMDA) para indução de pré-condicionamento químico (Tese). Santa Catarina: Universidade Federal de Santa Catarina; 2012. 88 p. http://repositorio.ufsc.br/xmlui/handle/123456789/96458

22. Bock H. Perfil ontogenético da transcrição de subunidades do receptor $\mathrm{n}$-metil-d-aspartato (NMDA) em estruturas cerebrais de ratos (Tese). Rio Grande do Sul: Universidade Federal do Rio Grande do Sul; 2009.

https://www.lume.ufrgs.br/bitstream/handle/10183/18800/00073210 3. pdf? sequence $=1$ \&isAllowed $=y$

23. Barreto TMC. Fisiopatologia do envelhecimento cerebral e mecanismos anti-aging (Tese). Portugal: Faculdade de Ciências da Saúde, Universidade Beira Interior; $2020.254 \mathrm{p}$. https://ubibliorum.ubi.pt/bitstream/10400.6/10793/1/7605 16092.p df

24.Serafim FRP. A Relação entre a Reserva Cognitiva e as Funções Executivas no Envelhecimento Saudável (Tese) Portugal: Instituto de Ciências da Saúde, Universidade Católica Portuguesa; 2018; 73p. http://hdl.handle.net/10400.14/28288

25. Haam J, Yakel JL. Cholinergic modulation of the hippocampal region and memory function. J Neurochem 2017;142:111-21. https://doi.org/10.1111/jnc.14052

26.Erdo F, Denes L, Lange E. Age-associated physiological and pathological changes at the blood-brain barrier: A review. J Cerebr Blood Flow Metabol 2017;37:4-24. https://doi.org/10.1177/0271678X16679420

27. Morita M, Ikeshima-Kataoka H, Kreft M, Vardjan N, Zorec R, Noda M. Metabolic Plasticity of Astrocytes and Aging of the Brain. Int J Mol Sci 2019;20:941. https://doi.org/10.3390/ijms20040941

28.Cohen RA, Marsiske MM, Smith GE. Neuropsychology of aging. Handbook Clin Neurol 2019;167:149-80. https://doi.org/10.1016/B978-0-12-804766-8.00010-8

29. Neves GN, Da Silva D. Atividade física e o desenvolvimento da plasticidade cerebral. Fac Sant'Ana Rev 2019;2:158-69. https://www.iessa.edu.br/revista/index.php/fsr/index

30.Guimarães CHS, Malena LMA, Limborço-Filho M, Marins FR. Demência e a doença de alzheimer no processo de envelhecimento: fisiopatologia e abordagem terapêutica. Rev Saúde Foco 2018;10:942$55 . \quad$ https://portal.unisepe.com.br/unifia/wpcontent/uploads/sites/10001/2018/12/108 DEM\%C3\%8ANCIA-E-ADOEN\%C3\%87A-DE-ALZHEIMER.pdf

31.Dias MD. Envelhecimento cognitivo e memória: a doença de Alzheimer em foco (Tese). Rio Grande do Sul: Universidade de Santa Cruz do Sul; 2017; 41p. http://hdl.handle.net/11624/2578 
32.Lazarov O, Hollands C. Hippocampal neurogenesis: learning to remember. Prog Neurobiol 2016;138:1-18. https://doi.org/10.1016/j.pneurobio.2015.12.006

33.Yang $T$, Sun $Y$, Lu $Z$, Leak RK, Zhang $F$. The impact of cerebrovascular aging on vascular cognitive impairment and dementia. Ageing Res Rev 2017;34:15-29. https://doi.org/10.1016/j.arr.2016.09.007

34.Phillips C. Lifestyle Modulators of Neuroplasticity: How Physical Activity, Mental Engagement, and Diet Promote Cognitive Health during Aging. Neural Plast 2017:3589271. https://doi.org/10.1155/2017/3589271

35.Silva VAH, Seabra PRC. Cognitive stimulation in people with mental disorders in the community: an integrative review. Rev Bras Enferm 2020;73:1-9. https://doi.org/10.1590/0034-7167-2018-0192

36.Cheng ST. Cognitive Reserve and the Prevention of Dementia: the Role of Physical and Cognitive Activities. Curr Psychiatry Rep 2016;18:85. https://doi.org/10.1007/s11920-016-0721-2

37.Gomes ECC, Souza SL, Marques APO, Leal MCC. Treino de estimulação de memória e a funcionalidade do idoso sem comprometimento cognitivo: uma revisão integrativa. Ciênc Saúde Col 2020;25:2193-2202.

https://doi.org/10.1590/141381232020256.24662018

38.Toda T, Gage FH. Review: adult neurogenesis contributes to hippocampal plasticity. Cell Tissue Res 2018;373:693-709. https://doi.org/10.1007/s00441-017-2735-4

39.Stern Y, Barnes CA, Grady C, Jones RN, Raz N. Brain Reserve, Cognitive Reserve, Compensation, and Maintenance: Operationalization, Validity, and Mechanisms of Cognitive Resilience. Neurobiol Aging 2019;83:124-9.

https://doi.org/10.1016/j.neurobiolaging.2019.03.022

40.Poulose SM, Miller MG, Scott T, Shukitt-Hale B. Nutritional Factors Affecting Adult Neurogenesis and Cognitive Function. Adv Nutr 2017;8:804-11. https://doi.org/10.3945/an.117.016261

41. Hadada CN, Love MCN, Triebel K. Normal cognitive aging. Clin Geriatr Med 2013;29:737-52.

https://doi.org/10.1016/j.cger.2013.07.002

42. Toureiro e Paiva SM. A influência da nutrição na fisiopatologia do envelhecimento (Tese). Portugal: Faculdade de Medicina, Universidade de Coimbra; 2017. http://hdl.handle.net/10316/82672

43. Coelho TIS. Influência da Nutrição na Resposta Inflamatória e no Envelhecimento (Tese). Portugal: Faculdade de Medicina, Universidade de Coimbra; 2017. http://hdl. handle.net/10316/82419

44. Mcgrattan AM, McGuinness B, McKinley MC, Kee F, Passmore $\mathrm{P}$, Woodside JV, et al. Diet and Inflammation in Cognitive Ageing and Alzheimer's Disease. Current Nutr Rep 2019;8:53-65. https://doi.org/10.1007/s13668-019-0271-4

45. Madore C, Yin Z, Leibowitz J, Butovsky O. Microglia, Lifestyle Stress, and Neurodegeneration. Immunity 2020;52:222-40. https://doi.org/10.1016/j.immuni.2019.12.003 